\title{
Review: Conservation Biology in sub-Saharan Africa
}

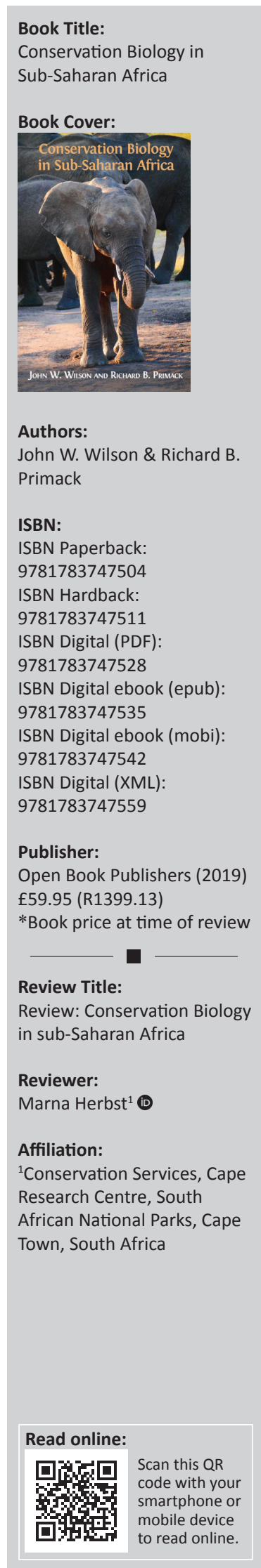

There are many well-written textbooks on biodiversity conservation. What makes this textbook so valuable is that it is 'the very first conservation biology textbook dedicated entirely to an African audience'. Conservation biology in Africa faces difficult and often unsurmountable challenges; the authors acknowledge these and describe it as a crises discipline! It might come across as overwhelming at first, however, the challenges are real and the authors manage to write with indepth understanding of these issues, in an African context, with explanations that young and practising African conservation biologists will relate to. Case studies and inspirational stories together with 'An Agenda for the Future' give guidance, foster a wider perspective and provide encouragement to readers.

The first three chapters present the general introduction of conservation biology in sub-Saharan Africa, followed by a chapter linking the human component and well-being into the field of conservation biology. In Chapter 1, the authors set the foundations for conservation biology, a multidisciplinary research field, where scholars need to reason within sound scientific principles and ethics to understand the broader societal environment and beliefs in which conservation biology functions. The authors reflect on the economic principles as well as the importance of communication to a wide audience. Chapter 2 sets the scene for a sub-Saharan context. It explains why the region is so diverse in terms of climate, geography and biodiversity. The authors succeed in discussing the historical context of Africa, the socio-political relationships and the history of conservation. They are cognisant of the relationship that the people of Africa have with nature, the use of resources and the influence of practices of the developed world. I must applaud the authors for opening discussions on the multitude of challenges the region is facing, and how solutions need to be sought that will benefit local communities in addition to conservation efforts to promote wildlife biodiversity. Chapter 3 explores the knowledge conservationists and ecologists need to define biodiversity, from species to ecosystems, and the various methodologies used in conservation biology to determine diversity and patterns in biodiversity. In Chapter 4, the connection and importance of people and nature, and how people value biodiversity, are described. This expands both the material benefits and regulating services to the non-material values and experiences people have in nature. Several examples of ecosystem services are presented in this chapter (i.e. the importance of wetlands in flood control, insects in pollination, biocontrol and the enjoyment of activities like scuba diving and wildlife viewing - all very relevant examples). The authors also touch on the sub-discipline of environmental economics and the contribution of ecosystem services to global economies.

After this broad introduction and developing an understanding of the underlining principles of conservation biology, the second part of the book follows with the threats to biodiversity and current scenarios, encouraging open-minded understanding and actions that are needed to address these challenges.

Chapter 5 starts with the very fitting title 'Scramble for Space', which emphasises the big conundrum of a growing human population as a driver for habitat loss, habitat degradation, fragmentation and the subsequent consequences that these factors have on remaining natural areas. The authors end with a request to readers to think about sustainable development and to reflect on the impact the expanding human population, with excessive consumption of natural resources, has on our lives. The current concerns about environmental change (anthropogenic climate change), and the impact of this on biodiversity, are discussed in Chapter 6. Drivers of climate change and the importance of understanding and predicting future changes on all ecosystems (terrestrial, freshwater and marine) are debated. The authors point out that climate change interacts with other drivers and that the resulting impacts, therefore, are exaggerated and that not all species will suffer to the same extent - some might even benefit. The important

Corresponding author: Marna Herbst, assoc.editor.koedoe@gmail.com

How to cite this book review: Herbst, M., 2020, 'Review: Conservation Biology in sub-Saharan Africa', Koedoe 62(1), a1635. https://doi. org/10.4102/koedoe.v62i1.1635

Copyright: (C 2020. The Authors. Licensee: AOSIS. This work is licensed under the Creative Commons Attribution License. 
message, that climate change has the means to affect the world and economies on a global scale, is highlighted. The topics for discussion in this chapter are very relevant and encourage readers to think clearly and deeply about these scenarios and mitigation actions. Chapter 7 continues with the threats to biodiversity from various forms of pollution, overharvesting, persecutions, invasive species, parasites and diseases. Although the authors touch on poaching under the theme of overharvesting, and again later (Chapter 12) under law enforcement, I do feel that this was the chapter where it may have been discussed in more depth. It is not just an overharvesting problem at issue, as the challenges involved are much deeper rooted in a social context. A stronger argument, with perhaps more controversial discussion points, could have highlighted this complex issue that is very explicit in African countries, the focus group of readers on Conservation Biology in Sub-Saharan Africa.

The last section of the book focusses on overarching solutions to the current biodiversity crisis. Chapter 8 reflects on the meaning of an extinction, what species are at risk, how to classify them (IUCN guidelines) and the use of these criteria to guide biologists and ecologists to focus on specific species and habitat-specific interventions and conservation efforts. In Chapters 9 and 10, the authors discuss applied conservation biology principles that are exercised in the conservation of species (Chapter 9) and ecosystems (Chapter 10). The authors explain how ecosystems can be restored through rehabilitation to a specifically identified benchmark state. Chapter 11 discusses how species' extinctions can be prevented, understanding threatened species and populations, the factors influencing them, how to maintain viable populations, and the feasibility and ethics involved when considering breeding or re-introducing species back into natural areas.

Chapter 12 touches on environmental laws and regulations. This is probably one of the more difficult themes to cover, however, the authors provide a good and thorough overview. The importance of international treaties, which guide national and local laws and regulations, are explained. Here the authors refer to poaching in a legislative context, which indeed needs discussing. I do however think it could have been emphasised more strongly in Chapter 7. Nonetheless, it is clear that the authors have a deep understanding of the challenges concerning the environmental laws and regulations of sub-Saharan Africa.

In Chapter 13, the importance of the prioritisation and declaration of protected areas (PAs) and the different management options and authorities involved (government, community, private or co-managed) are reviewed. The authors also reflect on the design and effective management of PAs. They acknowledge the significance of the interactions between PAs and the surrounding local communities, other stakeholders and the benefits of sharing and/or co-management opportunities that are critical to the existence of these areas. In Chapter 14, the authors focus their attention on the importance and values of areas and spaces outside PAs and their contribution to functioning ecosystems. Human welfare and biodiversity are interlinked, and green spaces in cities and environmentalfriendly farming practices contribute to economic benefits. The fact that conservationists depend on many of the extractive industries makes it important to explore working together and finding mutual balances for a healthier environment and being mindful of sustainable development. The human-wildlife conflict in Africa remains an important issue and it is imperative to find workable solutions (generally very case-specific). This chapter highlights several case studies on integrated conservation, development projects and community-based natural resource management. These examples are valuable for guidance in different scenarios that are playing out across sub-Saharan Africa.

In summary, conservation biology is indeed facing massive challenges and uncertainties. The goals range from describing biodiversity to species and environmental protection and restoration in the face of global threats and economic markets. In the last chapter of Conservation Biology in Sub-Saharan Africa, the authors set out an 'Agenda for the Future'. Sustainable development is essential as conservation biologists aim to address future needs without compromising the natural world. Finding a balance and making informed decisions about how to address the challenges for the future is the key message in this textbook. Being mindful that conservation funding continues to be limited, the authors show some optimism with ways to direct multilateral consortiums and non-governmental conservation organisations to support local conservation projects. Building partnerships and forming relationships with local people and conservation professionals remains important. The focus on environmental education, leadership, successful communication, media and the involvement of general citizens remains imperative in order for conservation biologists to succeed.

In Conservation Biology in Sub-Saharan Africa, the authors, with their background and understanding, were able to bring the basic principles of conservation biology together, and lead readers to understand the challenges and threats we face in the conservation of sub-Saharan Africa today. Through multiple case studies and guidance, it expands readers' perspective through real-life scenarios and challenges. With their writing skills and expertise, the authors have been able to produce an outstanding textbook. I am convinced that this book will be a fundamental resource for future conservation biologists and ecologists. It is published under a Creative Attribution International license, making this textbook accessible to all, which will be especially valuable in subSaharan African institutions. 